\title{
Fostering Students' Scientific Reasoning Skills in Secondary Education: An Intervention Study
}

\author{
Eli Janssen, ${ }^{1}$ KU Leuven, Belgium \\ Fien Depaepe, KU Leuven, Belgium \\ Ellen Claes, KU Leuven, Belgium \\ Jan Elen, KU Leuven, Belgium
}

\begin{abstract}
Equipping students with scientific reasoning skills (SRS) is an important mission of twenty-first-century education and part of the national curriculum in Flemish secondary schools. Therefore, we need to gain a better understanding of ways in which the development of these skills can be promoted. To date, empirical research on learning environments to foster SRS is scarce. In the present study, a quasi-experimental intervention study on SRS was designed and conducted with a sample of eleventh grade behavioral and social science students. Because of the complexity of SRS, two experimental conditions were compared with a control group. The experimental conditions were either analytic (five classes, $N=87$ ) or integrated (five classes, $N=101$ ) and are both based on the cycle of scientific inquiry, OPIRR (orientation, preparation, implementation, reporting, and reflection). In the analytic condition, on the one hand, SRS were trained in a fragmented way using unrelated exercises. In the integrated condition, on the other hand, a holistic approach was used whereby all the tasks were based on two authentic scientific papers. In the control group (two classes, $N=55$ ), teachers applied their existing methods in order to teach SRS. Results of this study show that participants in one of the experimental conditions developed significantly stronger SRS skills than participants in the control condition. There was no significant difference in SRS posttest results between both experimental conditions.
\end{abstract}

Keywords: Scientific Reasoning Skills, Secondary Education, Intervention, Instructional Design

\section{Theoretical Framework}

$\mathrm{S}$ cientific reasoning skills have been defined as twenty-first-century skills because they are an indispensable part of preparing students to solve problems in a highly complex and knowledge-based society (Halpern et al. 2012; Brew 2006; De Groof, Donche, and Van Petegem 2012; Fisher et al. 2014). As Engelmann, Neuhaus and Fischer (2016, 333) state, "Scientific reasoning skills are not just for researchers, they are also increasingly relevant for making informed decisions in our everyday lives." Furthermore, the level of mastery of SRS in secondary education is a significant predictor of success in higher education (Adey and Shayer 1994; Brew 2006). Previous research has shown that, already at a young age, children display specific behaviors that could be classified as precursors of SRS (Morris et al. 2012; Zimmerman 2000). Strangely enough, older children and adults often lack the ability to use SRS in everyday life, e.g. to draw appropriate conclusions based on evidence (Morris et al. 2012). A possible explanation of these limited SRS is that these complex skills do not develop automatically and need well-designed learning environments to acquire higher-order skills like SRS (Morris et al. 2012; Boa et al. 2009). The aim of this paper is to contribute to the existing research by designing and evaluating systematically designed learning environment(s) for SRS and focusing on students in secondary education, and more specifically in our case: on students in a behavioral and social science track.

\footnotetext{
${ }^{1}$ Corresponding Author: Eli Janssen, Parkstraat 45, bus 3602, 3000 Leuven, Centre for Political Research, KU Leuven, Leuven, 3000, Belgium. email: eli.janssen@kuleuven.be
}

The International Journal of Sciences, Mathematics and Technology in Learning Volume 26, Issue 1, 2019, http://thelearner.com 


\section{Conceptualization of Scientific Reasoning Skills}

Definitions of SRS often focus on the importance of SRS for scientific knowledge building; the skills important for scientific inquiry; and the importance of (domain-specific) knowledge for SRS. What ties these definitions together is that they mention a set of skills (and related knowledge) which can be connected to the various stages of the cycle of scientific inquiry. This is the cycle scientists pass through when performing research with the purpose of solving problems and/or coming to (new) conceptual knowledge and change. Authors like Zimmerman $(2005,1)$ refer to SRS as important skills to come to research-based conceptual change and knowledge construction: "the thinking skills involved in inquiry, experimentation, evidence evaluation, inference and argumentation that are done in the service of conceptual change or scientific understanding." Similar skills are also reflected in the definition of scientific reasoning by Morris et al. $(2012,61)$ : "Scientific reasoning encompasses the reasoning and problem-solving skills involved in generating, testing and revising hypotheses or theories and in the case of fully developed skills, reflecting on the process of knowledge acquisition and knowledge change that results from inquiry activities."

An influential framework presenting scientific inquiry cyclically, is the Scientific Discovery as Dual research model (SDDS) developed by Klahr and Dunbar (1988). In this SDDS model, three different stages of scientific discovery are presented namely hypothesis generation, evidence generation, and evidence evaluation (Opitz, Heene, and Fischer 2017). There are, however, a few critiques addressed to this SDDS model. Firstly, some authors advocate that more stages should be taken into account in the SDDS model, e.g. "concluding." Secondly, the model focuses strongly on experiments as the ultimate scientific method, leaving other scientific methods (such as observations) underexposed. Thirdly, the SDDS model puts a great emphasis on the generalizability of SRS while not paying attention to the importance of domain-specific knowledge in scientific reasoning (Opitz et al. 2017).

A framework quite similar to the SDDS model, called the OPIRR cycle, counters some of these remarks. OPIRR is an abbreviation describing the different stages and corresponding skills when performing scientific inquiry: Orientation (e.g. defining a scientific problem), Preparation (e.g. generating hypotheses), Implementation (e.g. conducting an experiment, gathering, and analyzing data), Reporting and Reflecting (e.g. concluding from the data). The OPIRR cycle is often used in Flemish education to present the process of scientific discovery (De Groof et al. 2012). This framework takes into account more steps in scientific inquiry than the SDDS model and is applicable to a large range of research methods. The OPIRR framework is visualized as an iterative circle, see Figure 1, referring to the iterative relation between the different steps. In practice, the $\mathrm{R}$ of reporting and reflections is discussed jointly. 


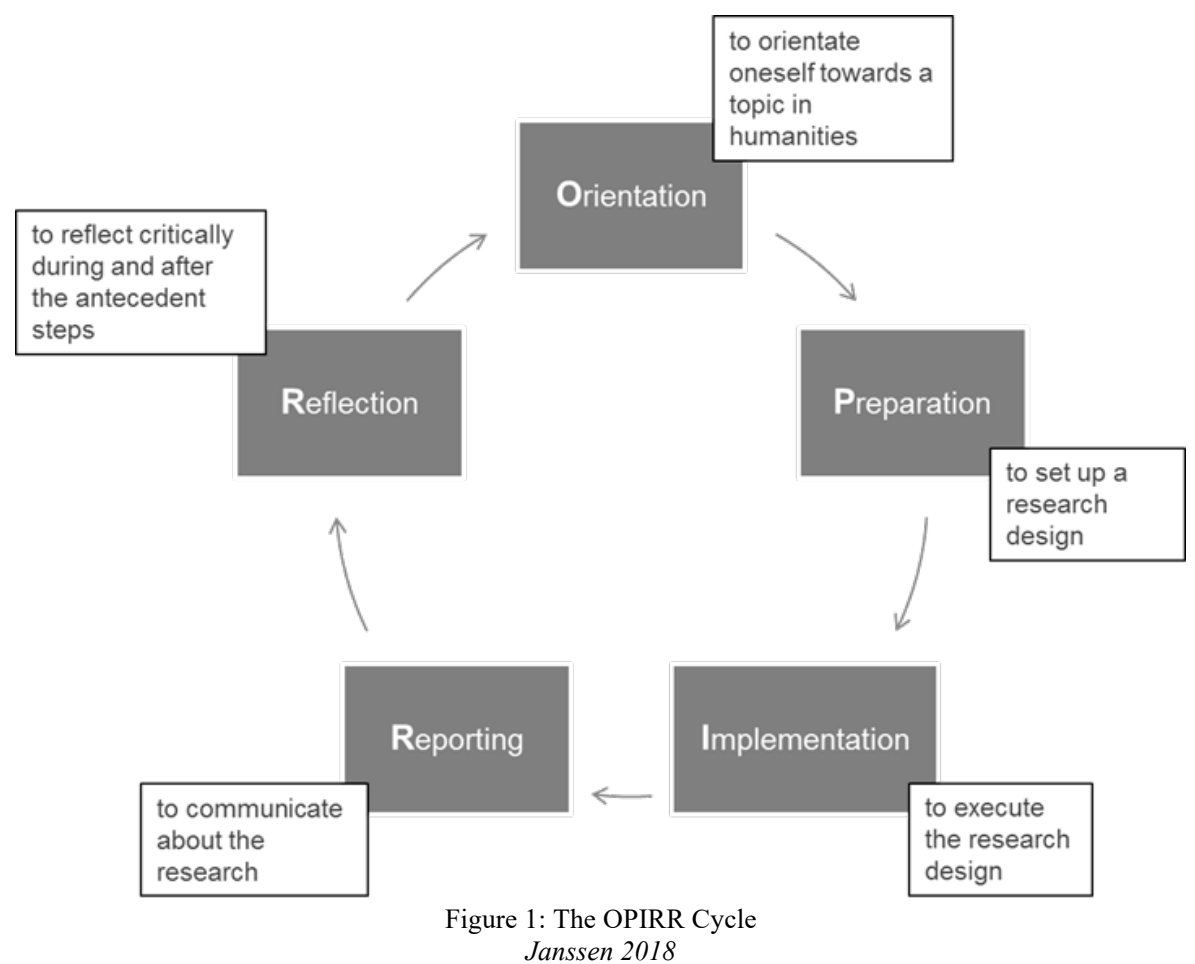

\section{Domain-Specificity versus Domain-Generality of SRS.}

In her review about scientific reasoning, Zimmerman $(2005,5)$ distinguishes two approaches to foster SRS. One being domain-specific "focusing on the development of conceptual knowledge in particular scientific domains" and the other being a general approach "focused on the reasoning and problem-solving strategies involved in diverse activities such as hypothesis generation, experimental design, evidence evaluation and drawing inferences." Scholars supporting the general approach argue that SRS can be employed in varying contexts, e.g. to interpret graphs and tables, whereas scholars supporting the domain specific approach to SRS (Fisher et al. 2014; Wagner, Garner and Kawulich 2011; Zimmerman 2000), argue that different disciplines may require the application of different rules, e.g. concerning what counts as evidence (Engelmann et al. 2016; Fisher et al. 2014; Zimmermann 2000). In addition, the scientific discipline also determines the use of a certain kind of research method. In the context of behavioral and social science research, the use of interviews is perceived as a valid and reliable way to gather data. However, in natural sciences such as physics and chemistry interviews are used far less often to gather data. This implies researchers know the rules specific to a certain discipline. In their review Opitz et al. (2017) state that there is a growing interest in combining both approaches, studying the interaction between domain-specific knowledge and general scientific abilities.

The main focus of this article is on enhancing individuals' SRS (skills needed for scientific inquiry) in a domain-specific context (behavioral and social science), using a domain-general model, the OPIRR cycle. In the next paragraph, the OPIRR cycle is linked to the Flemish attainment goals concerning SRS. 


\section{SRS as Part of Formal Science Education}

Given the assumption that the development of SRS can contribute to more critical and civically engaged citizens and can deliver more competitive workforces (Osborne and Dillon 2008; The Royal Society 2014), there is a growing interest in SRS. Also, in the international testing tradition of PISA, the importance of SRS becomes clear, as fifteen year olds are not only tested about their knowledge and skills in mathematics and language, but also regarding their level of scientific literacy (combining SRS and understanding of the nature of science) (OECD 2006).

The Flemish government has defined final attainment targets for all tracks in upper secondary education. The following final attainment targets concerning SRS are defined by the Flemish Ministry of Education and Training (2016) for the behavioral and social science track:

- "Students can orient themselves around a research problem by collecting, organizing and editing information."

- "Students can prepare, execute and evaluate a behavioral and social science research problem."

- "Students can report on the results of research in behavioral and social science (including discussions that include different points of view)."

As can be noticed, these attainment goals reflect a skills-based view on SRS. As a consequence, these goals can be directly linked to the different stages of the OPIRR cycle. While the first attainment goal refers to the orientation phase of the OPIRR cycle, the second goal refers to the skills necessary to prepare (phase 2) and execute/implement (phase 3) research. The last goal refers to the reporting phase in the OPIRR cycle. As mentioned above, reflection takes place during the entire process of scientific inquiry, also reflected in the attainment goals mentioning terminology like "editing," "evaluating," and "different points of view."

Although the first attainment goal is formulated in a more general way, not referring to a specific domain, the two latter attainment goals explicitly refer to the use of these SRS in behavioral and social science. The Flemish government thus seems to have adopted a mixed view on SRS combining the importance of domain-specific knowledge with more general SRS abilities. In the following section, ways to promote these SRS will be discussed along with a short summary of the empirical research already performed on this topic.

\section{Fostering SRS through Complex Learning}

Van Merriënboer and Kirschner (2007, 244) define complex learning as "the integration of knowledge, skills and attitudes; coordinating qualitatively different constituent skills; and often transferring what was learned in school or training to daily life and work." Learning how to go through the different steps of the circle of scientific inquiry responds to this definition of complex learning. In order to perform scientific inquiry, one needs a certain amount of knowledge (domainspecific and domain-general). Moreover, the coordination of SRS skills is a prerequisite of good scientific inquiry. These SRS can be used in different settings and everyday life (e.g. solving a problem). In addition, scientific inquiry is a demanding process asking for certain attitudes of the inquirer, like persistence

The four-component instructional model (4C/ID model) by van Merriënboer (1997) proposes a framework to design suitable learning environments for complex learning. The instructional design model defines four components: learning tasks, supportive information, procedural information, and part-task practice (van Merriënboer and Kirschner 2007). Learning tasks are meaningful authentic whole-tasks. These meaningful tasks are introduced to the students and students are expected to perform these tasks successfully at the end of the sessions. In case of SRS, this authentic whole-task could be: performing an experiment from start to finish. Supportive information is the information students need to incorporate in addition to their prior knowledge in 
order to ensure that they can perform the task rigorously. This could be, for example, previous research about variables they would like to use in their experiment. Procedural information is justin-time information that informs students how certain tasks can/should be done. This information is internalized by students when practicing a specific task and thus will be automatized after a particular time period. Applied to SRS, this could be specific support while executing statistical analysis like an ANOVA. Part-task practice is used to further train students in specific skills, which should be automated, without completing the whole-task at once. Reasoning with students on how to choose the best research method when setting up a research could be an example of this parttask practice. The 4C/ID model is interesting because it presents tasks and skills in an integrated way to the learner and because the level of guidance is decreased in a systematic way.

\section{The Presentation of Tasks, Atomistic versus Holistic.}

Van Merriënboer and Kirschner (2007) distinguish between two types of learning designs. The first one is an atomistic learning design, where complex skills are split up into a number of simple and small parts, and these fragmented skills are accumulated in the design. The reduction used in the atomistic design is efficient when there are few interconnections between the different elements of the subject matter. The second is the integrated learning design, designs that pay attention to the interconnectedness between the different skills and tasks. In a holistic design, different skills and tasks are framed in the bigger picture making students more aware how these tasks are interdependent. It is assumed that a holistic design is more beneficial for learning complex skills because an atomistic design loses sight of the complexity of the whole-task and fails to show the interconnections between skills being taught. The whole-task/holistic approach using the 4C/ID model seems to fit nicely when teaching SRS for many reasons. Firstly, the reciprocal nature of the different steps of the OPIRR cycle requires that students see the bigger picture (De Groof et al. 2012). That way, they will become aware of the different skills they have to use simultaneously when they set up a research themselves. Secondly, students get more insight into where knowledge comes from (metacognitive knowledge) and how it is built. Thirdly, the whole-task/holistic approach is supposed to focus more strongly on the transfer of SRS to unfamiliar tasks (van Merriënboer and Kirschner 2007). Advocating for this whole-task design does not imply, however, that part-task instruction is banned from the whole-task design idea. The training of subskills using part-task practice is still an essential part of the instruction, however, the use of these subskills is always framed in a more prominent and authentic task. Furthermore, a holistic/whole-task design, starting from an authentic example, can create a more meaningful context for learners, which can stimulate the development of SRS (Lim, Reiser, and Olina 2009; Zimmerman 2005). In a design that accumulates fragmented skills, it is far more difficult for learners to see the usefulness of what they have learned for real-life situations.

\section{Level of Guidance}

Another central assumption in the 4C/ID model is that a gradual reduction of the level of student guidance (supporting students in several ways) works best and enables students to perform the whole-task themselves in the long run. This implies a rather intensive guidance in the early stages of the learning process (Rijborz 2003). In summary, when designing learning environments for complex skills like SRS, an integrated approach consisting of an inquiry format combined with rather strong guidance of students is desirable, especially when prior knowledge is limited (Kirschner, Sweller, and Clark 2006; van Merriënboer and Kirschner 2007). 


\section{Empirical Studies on Fostering SRS}

Intervention studies on SRS do indicate that the acquisition of SRS by students can be promoted effectively (Engelmann et al. 2016; Fisher et al. 2014; Furtak et al. 2012; Lazonder and Egbrink 2014; Osborne 2010). Empirical research however, often takes an atomistic stance on SRS, zooming in on the development of one specific skill, e.g. the control of variables strategy (CVS) (Babai and Levit-Dori 2009; Halpern et al. 2012; Lazonder and Egbrink 2014; Lorch et al. 2014; Stark, Puhl and Krause 2009, Zimmerman 2005). For example, intervention studies on CVS investigate the level of guidance and task segmentation needed to promote student's ability to design unconfounded experiments (Klahr et al. 2011; Lazonder and Egbrink 2014; Lorch et al. 2014).

Another problem with the existing intervention studies on SRS is the lack of information on the designs used in intervention studies on SRS. Making it difficult to identify what makes these interventions effective for SRS. For example, no intervention studies mentioning the use of the 4C/ID model for the design of SRS learning environment could be identified. Lazonder and Harmsen (2016) performed a meta-analysis on the effects of the level of guidance on inquiry-based learning. These authors looked at seventy-two studies and found that guidance has a facilitative effect on learning activities, performance success, and learning outcomes. However, their sample of studies was too small to be able to differentiate effects according to the type of guidance (Lazonder and Harmsen 2016).

Lastly, empirical research on SRS tends to focus more on so-called STEM students who study science, technology, engineering, and mathematics (Boa et al. 2009; Opitz et al. 2017). This can be partially explained by the fact that scientific reasoning is often strongly associated with being able to perform experiments, a dominant research method in fields of study belonging to STEM.

A last issue taps into the SRS instruments that can be used to evaluate designed SRS learning environments. In the past forty years, several test instruments have been developed, differing on multiple aspects: going from the number of skills tested, the multidimensionality of the SRS construct, the domain-specific or domain-general take on SRS, the psychometric properties of the test, to the test format and the age these tests are developed for (Opitz et al. 2017). Skills most frequently measured in SRS tests are hypothesis generation, evidence generation, evidence evaluation and drawing conclusions, in the more recent tests questioning is often added to this list. Test instruments developed for a behavioral and social science context are scarce, as is illustrated in the review of Opitz et al. (2017) where only one test of the thirty-eight tests included in the review was specifically developed for this field of study.

\section{Problem Statement}

The Flemish government has formulated attainment goals concerning SRS for the social and behavioral sciences track - a track preparing students for higher education - in upper secondary education, which means these goals should be met by each student. However, evidence suggests that not all students achieve these goals (De Groof et al. 2012; Morris et al. 2012; Sermeus et al. 2017). Formal education nowadays fails to develop SRS in students and teachers experience difficulties in supporting students to acquire SRS (Osborne and Dillon 2008; De Groof et al. 2012; Rijborz 2003; van Tilburg and Verloop 2000). Hence, there is a need for design-based intervention studies targeting appropriate ways to enhance SRS in secondary education (Wagner et al. 2011). Existing empirical research on the effects of interventions on SRS is often atomistic in nature, focused on specific contents or skills of SRS, e.g. formulating a sound research question (Engelmann et al. 2016). Therefore, this study takes a more holistic view on SRS and discusses the iterative circle of scientific inquiry (Zimmerman 2005), thus accounting for the complex nature of these SRS skills. The field of behavioral and social science was chosen to complement the abundance of SRS research among students in natural sciences, e.g. biology, chemistry, and physics (Alake-Tuenter 2014; De Groof et al. 2012, Opitz et al. 2017; Osborne and Dillon 2008). 


\section{This Study}

A quasi-experimental pretest-posttest intervention study was set up to evaluate the effectiveness of two interventions oriented at supporting SRS development: the use of an instructional design principles, i.e. 4C/ID model is investigated compared to a control condition not stating to use this 4C/ID model; and the integrated condition is compared to a more analytic condition. There were two experimental conditions, i.e., analytic and integrated condition. In the analytic condition, participants were taught about the OPIRR cycle training their skills in a fragmented way. Noninterlinked examples and exercises were used to practice part-task SRS per phase of the OPIRR cycle. In the integrated condition, participants discussed two authentic research papers using the OPIRR cycle as a guiding framework. Participants reflected on the research design of both studies, the decisions the authors made in each phase of the OPIRR cycle, and critically discussed the inconsistencies. Both conditions were designed with a high level of guided instruction. The following research questions (RQ) were formulated.

RQ1: Is there a difference in developed SRS between students that followed the 4C/ID based courses and students in the control condition?

RQ2: Do students in the integrated (whole-task) condition develop better SRS than students in the analytic condition (part-task)?

It was expected that students in the integrated condition would develop better SRS because the integrated design starts with a whole task, discusses authentic research papers, and makes explicit links between different stages of the OPIRR cycle, which is more in line with designs for complex learning (van Merriënboer and Kirschner 2007). The analytic condition was based on an accumulative design focused on part-task practice of fragmented skills and, as such, reduces the complexity of the real scientific reasoning process. However, it is expected that participants in the analytic condition will still develop better SRS than participants in the control condition because of the systematic design of the learning environment using the 4C/ID model and the intensive guidance foreseen in this condition.

\section{Method}

\section{Design of the Learning Environments}

In the next part, similarities and differences between the experimental conditions will be discussed. For clarification, Table 1 provides a comparison between tasks used in the analytic and integrated condition.

\section{Similarities}

The analytic and integrated condition are based on the same design principles (4C/ID model), use the same framework of scientific inquiry (i.e. the OPIRR cycle), have the same kind of SRS being taught (e.g. formulating a research question), are in the same field of study (i.e. behavioral and social science), use the same level of guidance, have the same performed learning activities, have the same duration of the intervention, and have the classroom teacher as executer of the intervention. Firstly, the SRS practiced are directly linked to the OPIRR cycle and are thus identical in both conditions. This framework was chosen because it comprises the SRS necessary to complete the full cycle of scientific inquiry (De Groof et al. 2012). Furthermore, the OPIRR cycle is a domain-general framework usable in different contexts, which could enable transfer of participants' SRS. Secondly, since the intervention took place in a behavioral and social science track, designed course materials in both conditions discussed psychological, educational, and sociological topics. Thirdly, in both experimental conditions, guided instruction was used to 
introduce the different concepts and skills concerning the research process. For example, participants were asked to evaluate research questions in groups, were asked to come up with a research question, and, accordingly, were to design an experiment that could answer this research question. This choice was made because of the low prior knowledge of the participants. Other epistemic activities like problem identification, hypothesis generation, looking for possible flaws in designs, qualitative analysis, drawing conclusions, and interpreting quantitative/qualitative evidence were part of both experimental conditions (Fischer et al. 2014). Lastly, in both conditions, interventions took thirteen sessions of one hour spread over the first semester (approximately two hours a week).

\section{Difference}

In the holistic design, participants were introduced with a whole-task, studying two authentic scientific papers. These papers were published in a Dutch journal for behavioral and social science. The qualitative research paper discussed the importance of resources in the school career of pupils (van de Koot-Dees, Rodriques and Terwel 2011). The quantitative research paper discussed the relationship between children and their (step)dads (Hakvoort et al. 2011). Exercises focused on the integration of different phases of the OPIRR cycle and the analysis of the design of the two studies (papers) under discussion. In the analytic condition, an accumulative design of part-task skills was used, where each of the exercises was designed to train one specific skill (important in a certain phase of the OPIRR cycle).

\section{Control Condition}

Teachers in the control condition used their own materials and lesson plans. As SRS are part of students' attainment targets, these materials already existed and were used in previous years to prepare students' SRS. As teachers in Flanders have great freedom in terms of how they achieve the attainment targets, designs between classes in the control condition varied. In order to grasp what happened in these conditions, observations of the lessons were complemented by teacher interviews and document analysis. In the first control class, teachers devoted thirteen sessions of fifty minutes to the differences between science and pseudoscience. Students worked in groups on several tasks (analyzing texts, preparing a debate, etc.) linked to this theme. In the second control class, students designed their own research in small groups (four-to-five students). In between the pretest and posttest, the students chose a topic of interest, started a literature review, and formulated a research question. As in the experimental condition, the SRS sessions were part of the behavioral and social science course taught in the first semester. 
Table 1: Comparison of the Tasks Performed in the Analytic and the Integrated Condition

\begin{tabular}{|c|c|c|}
\hline & Analytic Condition & Integrated Condition \\
\hline Orientation & $\begin{array}{l}\text { Read the following research } \\
\text { questions (RQs): } \\
\text { - Are these RQs well } \\
\text { formulated? } \\
\text { How can these RQs be } \\
\text { improved? (using the } \\
\text { guidelines discussed) }\end{array}$ & $\begin{array}{l}\text { Identify the RQs formulated in the scientific } \\
\text { articles: } \\
\text { - Are the RQs well formulated? } \\
\text { - How could these RQs be improved? } \\
\text { (using the guidelines discussed) } \\
\text { Can you think of other RQs which } \\
\text { would also be interesting based on the } \\
\text { introduction of both articles? }\end{array}$ \\
\hline $\begin{array}{l}\text { Preparation } \\
\text { "The Research } \\
\text { Design" }\end{array}$ & $\begin{array}{l}\text { In the following exercise, four } \\
\text { different questions/situations are } \\
\text { explained, try to match each } \\
\text { explanation with a suitable } \\
\text { research design and motivate your } \\
\text { choice. } \\
\text { - Sally wants to find a } \\
\text { successful method to help } \\
\text { gamblers get rid of their } \\
\text { addiction. What type of } \\
\text { research design should she } \\
\text { use? }\end{array}$ & $\begin{array}{l}\text { Read the methodological part of the research } \\
\text { paper. } \\
\text { - What research design was used in } \\
\text { - Can we answer the research } \\
\text { questions using this design? Why } \\
\text { do you think so? } \\
\text { - Could another type of design be } \\
\text { used? What would it look like? } \\
\text { Motivate why this design is also } \\
\text { suitable to use. }\end{array}$ \\
\hline $\begin{array}{l}\text { Implementation } \\
\text { "Coding" }\end{array}$ & $\begin{array}{l}\text { On the next page, you can read a } \\
\text { fragment of a transcript of an } \\
\text { interview. Try labeling parts of the } \\
\text { transcript with codes. } \\
\text { De codenames are given. }\end{array}$ & $\begin{array}{l}\text { What would an observation scheme for } \\
\text { variable X of article A look like? } \\
\text { - Try putting together an observation } \\
\text { schema that could be used by the } \\
\text { authors and discuss it with your } \\
\text { neighbor. } \\
\text { - Which codes will you use and } \\
\text { why? } \\
\text { Are you able to answer the research } \\
\text { question based on the scheme you } \\
\text { are planning to use? }\end{array}$ \\
\hline $\begin{array}{l}\text { Reporting } \\
\text { "Scientific } \\
\text { Poster" }\end{array}$ & $\begin{array}{l}\text { Link the elements on the scientific } \\
\text { poster of a study to the different } \\
\text { phases of the OPIRR cycle. } \\
\text { - What structure is used? }\end{array}$ & $\begin{array}{l}\text { Try to make a scientific poster based on } \\
\text { research article A. } \\
\text { Compare your own poster to an } \\
\text { example? What is missing in your } \\
\text { own poster? Why is this element } \\
\text { important? }\end{array}$ \\
\hline $\begin{array}{l}\text { Reflection } \\
\text { "Validity" }\end{array}$ & $\begin{array}{l}\text { In the next exercises, you will get } \\
\text { some short descriptions of } \\
\text { situations where there is a problem } \\
\text { with the validity of the research. } \\
\text { - Try to identify what type of } \\
\text { validity is violated in the } \\
\text { given examples. }\end{array}$ & $\begin{array}{l}\text { What about the validity of the two studies } \\
\text { under discussions? } \\
\text { - Where could possible problems with } \\
\text { validity be situated? What types of } \\
\text { validity are violated then? } \\
\text { Do the authors discuss these problems } \\
\text { anywhere in the article? } \\
\text { How could these problems with } \\
\text { validity have been avoided in a } \\
\text { previous stage of the research cycle? }\end{array}$ \\
\hline
\end{tabular}




\section{Participants}

Teachers voluntarily participated in the study and were randomly assigned to one of the two experimental conditions. Teachers in the control condition chose not to alter their teaching approach, but were willing to have their students take the instruments. All classes that participated in this project were situated in urban schools. Students were enrolled in the eleventh grade (sixteento-seventeen years old) of a general behavioral and social science track. These students took a course on behavioral and social science at least three hours a week; the SRS sessions were organized during these courses. After observations, one teacher in the integrated condition was removed from the data sample because the teachers' interpretation of the teacher manual differed greatly from the initial design. Without this teachers' class, five classes participated in the integrated condition, five in the analytic condition, and two in the control condition.

\section{Instrument}

In assessing the scientific reasoning skills of the participating pupils in this study a domain-specific SRS pretest and posttest was used (Sermeus et al. 2017). This SRS test is a hands-off, open-ended questions test, developed to measure students' SRS and scientific knowledge in upper secondary education. The following SRS are covered in the test used: hypothesis generation, evidence generation, evidence evaluation, drawing conclusions, and questioning. This test is domainspecific as questions are embedded in behavioral and social science topics. Each test is comprised of ten main questions, which are in some cases further divided into sub-questions. The SRS test items can be linked to the OPIRR cycle see Table 2 .

Pretest and posttest items were composed to be comparable in the sense that they focus on similar kinds of knowledge and skills in different situations, see Figures 2 and 3. The internal consistency of both pretest and posttest was rather low. The pretest's Cronbach's $\alpha$ is .47 , and the posttest's Cronbach's $\alpha$ is .50. Because of this low internal consistency of the tests used, results should be interpreted carefully.

Answers on the pretest and posttest were coded by two independent coders using the same scoring guide. In an early stage, differences in scoring were discussed and agreements were made to ensure uniform coding. When sufficient interrater reliability had been established, the tests were divided among the two coders. Interrater reliability was calculated with a weighted kappa coefficient and evaluated following the classification presented by Altman (1991). The overall interrater reliability of the pretest and posttest was high with a $\kappa$ (Kappa) of .84 and 87.

Table 2: Distribution of the OPIRR Phases over the Questions in the Tests

\begin{tabular}{|l|l|l|l|}
\hline Question & OPIRR Phase & Pretest Points & Posttest Points \\
\hline Q1-Q3 & Orientation & 11 & 12 \\
\hline$Q 4-Q 5$ & Preparation & 3 & 3 \\
\hline$Q 6-Q 7$ & Implementation & 5 & 4 \\
\hline$Q 8$ & Reflection & 5 & 5 \\
\hline$Q 9$ & Reporting & 4 & 3 \\
\hline Q10 & Reflection/Transfer & 3 & 3 \\
\hline Total & & 31 & 30 \\
\hline
\end{tabular}

Source: Janssen 2018 
Question 3A

Below are four questions that can be asked by a researcher at the start of a research into the growing number of members in youth organizations.

A. Why did the number of members in youth organizations in Belgium increase over the last 10 years?

B. Why did so many young people enroll in a youth organization recently?

C. Why are there so many parents enrolling their children in a youth organization over the last five years?

D. Why are parents forcing their children to go to a youth organization?

Which research question do you think is best? Explain why.

Figure 2: Example of Pretest Question

Source: Data Adapted from Sermeus 2017

Question 3B

Research shows that in Belgium $5 \%$ of the population goes to church every week, and $57 \%$ of newborns are baptized. Below are four questions that can be asked by a researcher at the start of a study on the choice for baptism.

A. Why do people baptize their children based on tradition?

B. Why are people still baptizing their children despite recent scandals in the church?

C. Why do people that don't go to church on a weekly basis still baptize their children?

D. Why do non-believers baptize their children?

Which research question do you think is best? Explain why.

Figure 3: Example of Posttest Question

Source: Data Adapted from Sermeus 2017

\section{Procedure}

An SRS pretest was taken a few days before the start of the SRS course in all participating classes. The designed content of thriteen sessions was taught during the subject Behavioral and Social Science with two sessions (each fifty minutes) a week during the first semester. The SRS posttest was administered in the week after the final SRS session; see Figure 4. Time to complete each SRS test was limited to one lesson (fifty minutes). Independent administrators were trained by the researchers. Teachers were not allowed to help their students during the SRS tests. Due to ethical constraints, the participants of this study were informed in advance that individual test scores would not be communicated to their teachers and that the scores thus could not be used as part of their evaluation or as a grade for the subject.

Each teacher participating in the project (experimental and control) was observed at least once during the semester when teaching an SRS session. These observations helped to shed light on the extent to which teachers followed the guidelines in the manual and how well teachers coped with the teaching materials.
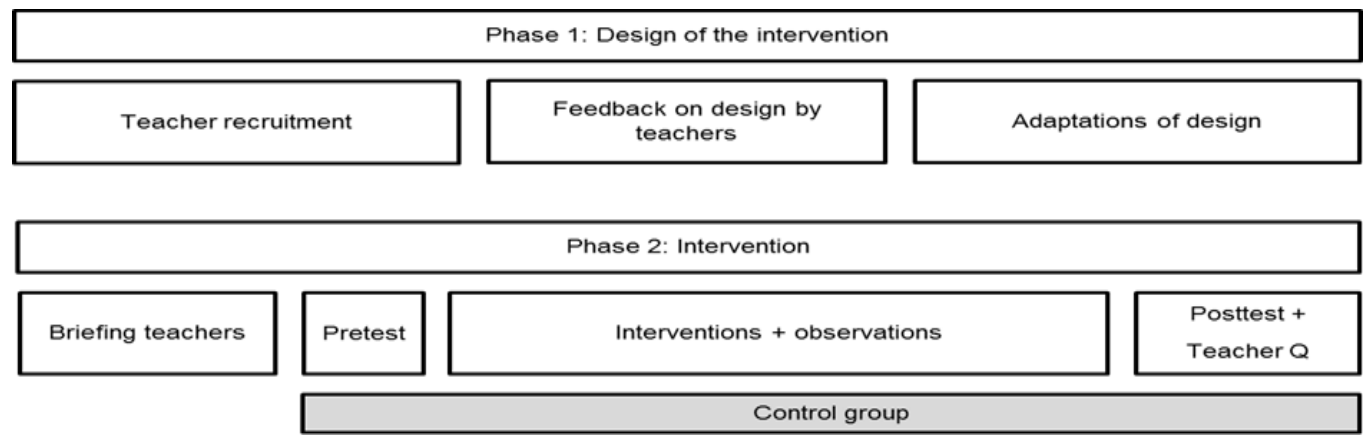

Figure 4: Schematic Representation Course of the Study Source: Janssen 2018 


\section{Data Analysis}

All students were able to complete the pretest and posttest in the time provided. Participants were removed from the data matrix when they were absent at either the pretest or posttest. The control condition had the most missing data $(\mathrm{N}=13)$, followed by the analytic condition $(\mathrm{N}=11)$ and the integrated condition $(\mathrm{N}=8)$. Four participants in the integrated condition were removed from the data sample because the participants' posttest scores were less than three standard deviations under the group's mean score. One participant in the integrated condition was removed as his/her score was three standard deviations above the group's mean score. A total number of 243 participants took part in both the pretest and the posttest and were incorporated in the dataset. Most participants were in the integrated condition $(\mathrm{N}=101)$ followed by the analytic condition $(\mathrm{N}=87)$ and the control condition $(\mathrm{N}=55)$. Because the behavioral and social science track attracts far more girls than boys, the sample contains 78 percent girls and 22 percent boys.

A one-way ANOVA was performed with the intervention as the independent variable (to test for the main effect of intervention) and the SRS posttest score as the dependent variable. In the next phase, assumptions to do a one-way ANOVA were checked. There was no violation of the assumptions of normality, homogeneity of variance (Levene's $F(2,240)=2.07, p>.1$ ), linearity, homogeneity of regression slopes, and reliable measurement of the covariate. In this quasiexperimental study there is no random assignment of cases to populations (Stern 2011). This assumption is violated because participants (students) are nested in classes and therefore nested in schools. Teachers were, however, randomly assigned to one of the experimental conditions. Furthermore, because the three conditions were also compared with each other, a post hoc test with Bonferroni correction was used to correct for the effect of multiple comparisons.

\section{Results}

\section{Descriptives}

In Table 3, an overview of the number of participants, means, and standard deviations per condition can be found. Participants in the control condition have the highest mean score $(\mathrm{M}=11.35, \mathrm{SD}=3.04)$ on the SRS pretest. The mean scores of participants in the integrated condition $(\mathrm{M}=10.98 ; \mathrm{SD}=3.32)$ and analytic condition $(\mathrm{M}=10.80 ; \mathrm{SD}=2.82)$ are similar. Participants on average score only one-third of the maximum score of 31 points for the pretest, which indicates low prior SRS skills. The posttest scores reveal higher means for participants in the experimental conditions and a lower mean for participants in the control condition. Although scores are higher for students in the experimental conditions, they are still below half of the maximum score on the posttest (30 points).

Table 3: Descriptive Overview of the Means and Standard Deviations of the Scores on the Preand Posttest per Condition

\begin{tabular}{|l|l|l|l|}
\hline & $N$ & Pretest Score M(SD) & Posttest Score M (SD) \\
\hline Analytic & 87 & $10.80(2.82)$ & $12.36(3.16)$ \\
\hline Integrated & 101 & $10.98(3.32)$ & $11.42(2.56)$ \\
\hline Control & 55 & $11.35(3.04)$ & $9.80(2.83)$ \\
\hline \multicolumn{2}{|c|}{ Source: Janssen 2018 }
\end{tabular}

\section{Findings}

Analyses of the pretest scores revealed no significant differences in SRS between the three conditions $(\mathrm{F}(2,240)=0.52, \mathrm{p}>0.1)$. A normal ANOVA on the posttest scores showed a main effect of condition for the scores on the SRS posttest $\left(\mathrm{F}(2,240)=13.55, \mathrm{p}<.001, \mathrm{R}^{2}=.10\right)$. The post hoc test revealed there was a significant difference in posttest scores between the experimental 
conditions and the control condition. The analytic and the integrated condition scored significantly better than the control condition $(\mathrm{p}<.001)$. There was no significant difference between the integrated condition and the analytic condition $(p>.05)$, which indicates students in the integrated condition did not perform significantly better on the SRS posttest than students in the analytic condition. The graph representing the standardized scores in Figure 5 indicates that students in the control condition scored significantly lower on the pretest than on the posttest $(p<.001)$. At the same time, students in the analytic condition score significantly higher on the posttest compared to the pretest $(\mathrm{p}<.001)$. There is no significant difference for students in the integrated condition between the pre-and posttest scores $(\mathrm{p}>.05)$.

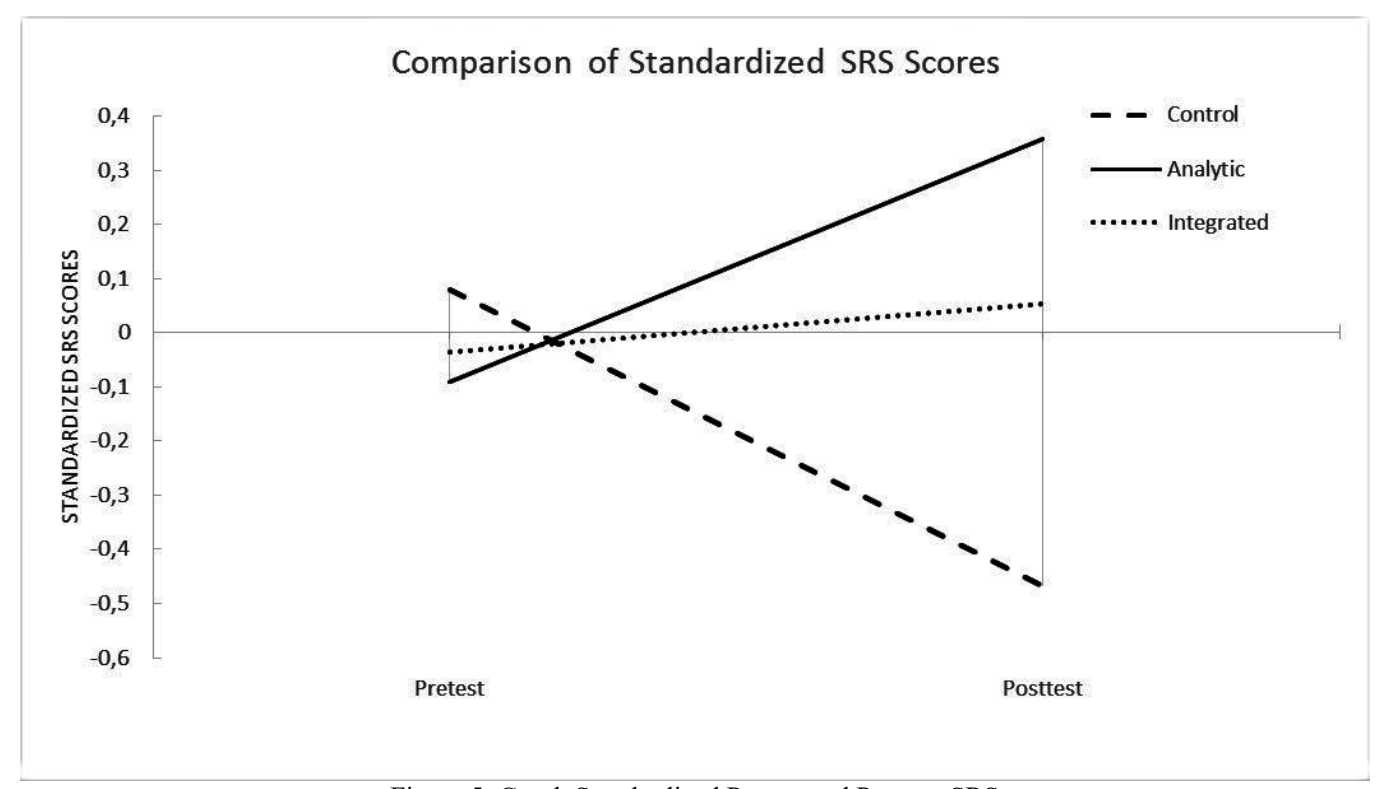

Figure 5: Graph Standardized Pretest and Posttest SRS Source: Janssen 2018

\section{Discussion}

In general, current formal education in secondary schools does not seem to succeed in developing students SRS to the fullest (Osborne and Dillon 2008). This poses a problem because secondary school students are supposed to be educated to be critical consumers of scientific knowledge (Osborne and Dillon 2008), and their success in higher education depends partially on their level of SRS when leaving secondary education (Brew 2006). Thus far, studies have been concerned with designing learning environments for SRS, often focus on one specific SRS skill, e.g. the formulating a good research question, instead of integrating different skills into one course and helping students to better understand the process of scientific inquiry (Zimmerman 2005). There is little empirical evidence on how these SRS can be fostered in students and what the effects are of the use of certain learning environments. Therefore, this study attempted to investigate whether students in a systematic designed learning environment, using the 4C/ID model, develop better SRS than students in a control condition. In addition, this study wanted to examine whether students develop better SRS in an integrated condition compared to an analytic condition.

A quasi-experimental pretest-posttest design with two experimental conditions was conducted to test the effect of an analytic and an integrated design on SRS compared to a control condition. Both experimental conditions were designed starting from the principles of the 4C/ID model and started with a high level of guidance in learning SRS necessary to perform scientific inquiry (according to the OPIRR cycle). Furthermore, both experimental designs combined domain- 
specific knowledge and domain-general skills. The analytic condition was designed using an accumulative design of fragmented skills, making sure participants practiced certain SRS one-byone using a variety of examples. After discussing one skill using part-task practice, teachers went on with the next one, working their way through the OPIRR cycle together with the students. Teachers involved in the integrated condition, on the other hand, started the course by presenting two scientific research papers to the students. From then on, all part-tasks were related to these two papers and skills were practiced using examples from this authentic material. The teacher regularly discussed the reasoning of the authors of the articles with the participants in order to demonstrate the interconnectedness of the different phases of the OPIRR cycle. Teachers in the control condition used their own lesson plan focused on reaching the Flemish attainment goals concerning SRS. A one-way ANOVA showed that participants in the experimental conditions scored significantly higher on the SRS posttest than participants in the control condition. There was no significant difference between students in the integrated and the analytic condition. Overall posttest scores of students in all conditions remained low. Some possible explanations for the results found in this intervention study are discussed in the following paragraphs.

Firstly, overall, the initial level of participants' SRS (performance on the pretest and posttest) was rather low; mean scores of students in different conditions did not, or barely exceeded, onethird of the maximum score. The initial level of SRS established at the onset of the study showed that the students were poorly trained in this respect during the earlier years of secondary schooling. The expected initial level of SRS of sixteen year olds was estimated too highly by the researchers. The complexity of the tasks at hand could have been too high given participants' lack of prior knowledge (Kirschner 2002).

Teachers in the integrated condition pointed out that the research articles used in the integrated condition were too long and rather complex for students in secondary education, even despite the fact that the articles were analyzed step-by-step during the thirteen sessions. Examples used in the analytic condition were shorter and more similar to what the participants are used to in secondary education. The lower difficulty of the examples in the analytic condition might have resulted in a better alignment between the participants' prior knowledge and the assigned tasks, resulting in less load and more mental effort (De Groof et al. 2012). These results are in line with the research of Grime (2012), who also found indications that among upper secondary school students with limited prior knowledge, it is better to first train and introduce SRS discretely, or in our terms, analytically, before using a more integrated approach. These findings can be linked to the pre-training principle used by Mayer (2005), who stresses the importance of ensuring that learners are familiar with the names and characteristics of key concepts when dealing with complex learning material.

In addition, teachers in the experimental conditions reported that the time constraints for the intervention were too tight. Mainly, teachers in the integrated condition reported that they did not have enough time to do an in-depth discussion of the research articles, forcing teachers to turn constructive and interactive learning activities in the integrated condition to passive and active learning activities, which take less time but are probably also less beneficial for the development of SRS (Engelmann et al. 2016).

Furthermore, teachers more often reported low motivation of participants in the integrated condition compared to the analytic condition. Possibly, the use of authentic research papers led to a higher exposure of the students to the complexity of scientific research. As Murtonen and Lehtinen (2005) pointed out, students often dislike the topic "research methods" because of the complex nature of research. Furthermore, in the designed sessions in this study, participants could not carry out their own research because of time constraints. Merrill $(2007,33)$ states that "learners integrating component knowledge and skills into a whole-task results in higher motivation and a better ability to apply the newly acquired skill in a new situation." In the designed sessions participants possibly did not experience enough freedom to experiment with doing research themselves. The idea of inquiry learning combined with teacher-led activities to stimulate the learning of the complex SRS skills comes into play. Letting students perform their own research 
in combination with adapted support and scaffolding by the teacher is defendable using the 4C/ID model for complex learning and the idea of integration of different SRS skills. In her review on SRS, Zimmerman (2005) also reports that a common factor in intervention studies is the use of a form of self-directed experimentation to integrate generals SRS and domain-specific content knowledge. Future intervention studies on SRS can perform longitudinal studies combining a form of inquiry learning (participants performing their own research) with teacher-led activities (e.g. Furtak et al. 2012).

\section{Limitations of This Study and Suggestions for Future Research}

\section{The OPIRR Framework}

Although the OPIRR framework is often used in Flemish secondary education to discuss SRS, this framework can be criticized in several ways. The sequencing of practical steps in the framework could hinder teachers grasping the true complexity and integration of the research process (Zimmerman 2005). Furthermore, this framework is strongly focused on knowledge and skills, leaving out necessary attitudes of a good researcher like curiosity and open-mindedness. Possibly, frameworks taking into account non-cognitive elements like motivation, conscientiousness, and dispositions could help to get insight into how students can be stimulated on the non-cognitive level to develop better SRS (Feist 2006).

\section{The Measurement of the SRS}

The SRS tests used in this study had a low internal consistency. This could be caused by the fact that different elements of SRS (skills used in the orientation, preparation implementation, reporting, and reflection phase) were measured using only a few items per phase. The SRS instruments were quite short because they were bound to strict terms concerning the time and the form of the test. Also, the participants scored rather low on the tests, causing low variability in test scores, making it more difficult to check for internal consistency. Secondly, the kind of test items used in the SRS test could have been in favor of participants in the analytic condition. Most items focused only on one skill and/or one type of knowledge. Test items were perhaps more recognizable for participants that were in the analytic design. Thirdly, the instruments were only used one week before and one week after the intervention. Effects could perhaps fade away when no effort is done to consolidate the acquired SRS (Lorch et al. 2014). Future research could focus on developing validated instruments trying to measure SRS in a more integrated and holistic way and adding a SRS retention test.

\section{The Teachers}

In support of the ecological validity of the study, interventions were performed by participants' own teachers instead of trained researchers. However, this makes the outcomes of the study vulnerable for differences in teachers, e.g., teachers interpretations of the manual. A few steps were taken to check if the enactment of the designed curriculum was done similarly by the teachers. Teacher manuals were rather comprehensive to make sure that teachers were well instructed. All teachers were briefed individually about the designed sessions and had the possibility to ask questions about the content of the intervention. Teachers were observed once or twice during the intervention, to assess how well they followed the teacher manual. At the start and the end of the intervention teachers were asked to give feedback (written and oral) on the intervention and to report about their experiences in class during the implementation of the sessions. All this information was used to get a proper view on the way teachers implemented the curriculum. The above, however, was insufficient for a profound analysis of the use of the designed materials. Further research could look at teachers' characteristics, which could influence the development of 
SRS in students. In addition, the level of confidence and experience that teachers have equally play an important role in transferring SRS. The information gathered during the intervention study shows that not all teachers feel skilled enough to teach the designed curriculum to their students. As Osborne and Dillon $(2008,9)$ state in their European report: "Good quality teachers, with upto-date knowledge and skills, are the foundation of any system of formal science education." According to Stokking et al. (2004), a lack of experience in teaching about research could lead to a stronger focus on the consecutive steps of research and a greater emphasis on disciplinary content. This could possibly explain why teachers in the integrated condition struggled more with the designed curriculum than teachers in the analytic condition. Future research could investigate the effects of interventions focused on strengthening teachers' SRS on the development of students' SRS.

\section{Conclusion}

Scientific reasoning skills are indispensable for twenty-first-century citizens. Current and future education can and will play an important role in supporting the development of these complex skills. However, as this study and other studies demonstrate, there is still a long road ahead. In order to investigate which features of the learning environment can foster complex skills like SRS, we set up an intervention study focusing on upper secondary education students in a behavioral and social science track. Despite the small sample, our study seems to indicate that the experimental conditions (integrated and analytic) have clear/promising benefits compared to the control condition. The added value of integrated conditions to foster students SRS is definitely worth further investigations, whereby learning environments are more adjusted to students' cognitive level and more adapted to their zone of proximal development. The results of this study do stress the importance of the alignment of part-task and whole-task practice and thus confirm the great importance of the design of the learning environment in fostering the development of SRS.

\section{Acknowledgement}

The authors would like to thank the teachers and students who participated in this intervention study and the academic training center for teachers (AVL) of the KU Leuven for funding this research. Furthermore they would like to thank Greet Louw for proofreading the article.

\section{REFERENCES}

Adey, Philip, and Michael Shayer. 1994. Really Raising Standards: Cognitive Intervention and Academic Achievement. London: Routledge.

Alake-Tuenter, Ester. 2014. "Inquiry-Based Science Teaching Competence of Pre-service Primary Teachers.” PhD diss., University of Wageningen. http://edepot.wur.nl/315471.

Altman, Douglas G. 1991. Practical Statistics for Medical Research. London: Chapman and Hall.

Babai, Reuven and Tamar Levit-Dori. 2009. "Several CASE Lessons Can Improve Students' Control of Variables Reasoning Scheme Ability." Journal of Science Education and Technology 18 (5): 439-46.

Brew, Angela. 2006. Research and Teaching: Beyond the Divide. Hampshire, New York: Palgrave Macmillan.

De Groof, Jetje, Vincent Donche, and Peter Van Petegem. 2012. Onderzoekend Leren Stimuleren: Effecten, Maatregelen en Principes [Stimulating Learning by Inquiry: Effects, Measures and Principles]. Leuven, Belgium: Acco. 
Engelmann, Katharina, Birgit J. Neuhaus, and Frank Fischer. 2016. "Fostering Scientific Reasoning in Education-Meta-Analytic Evidence from Intervention Studies." Educational Research and Evaluation 22 (5-6): 333-49. http://doi.org/10.1080/13803611.2016.1240089.

Feist, Gregory J. 2006. The Psychology of Science and the Origins of the Scientific Mind. New Haven, CT: Yale University Press.

Flemish Ministry of Education and Training. Secondary Education - Cross-Curricular Attainment Targets and Developmental Objectives - Specific Attainment TargetsBehavioral and Social Science-Research Competencies. Accessed December 23, 2016. https://www.kwalificatiesencurriculum.be/tweede-en-derde-graad-aso-cesuurdoelenhumane-wetenschappen.

Fisher, Frank, Ingo Kollar, Stefan Ufer, Beate Sodian, Heinrich Hussmann, Reinhard Pekrun, Birgit Neuhaus, et al. 2014. "Scientific Reasoning and Argumentation: Advancing an Interdisciplinary Research Agenda in Education." Frontline Learning Research 2 (3): $28-45$.

Furtak, Erin Marie, Tina Seidel, Heidi Iverson, and Derek C. Briggs. 2012. "Experimental and Quasi-experimental Studies of Inquiry-Based Science Teaching: A MetaAnalysis." Review of Educational Research 82 (3): 300-29.

Grime, Richard. 2012. "A School's Experience of the Discrete Teaching of Scientific Skills at Early Secondary Level.” School Science Review 94 (346): 99-102.

Hakvoort, Esther M., Henny M.W. Bos, Frank van Balen, and Jo M.A. Hermanns. 2011. "Kinderen in Stiefvadergezinnen: Relaties met Vaders en Stiefvaders" [Children in Stepfather Families: Relationships with Fathers and Stepfathers]. Pedagogiek [Pedagogy] 31 (1): 68-82.

Halpern, Diane F., Keith Millis, Arthur C. Graesser, Heather Butler, Carol Forsyth, and Zhiqiang Cai. 2012. "Operation ARA: A Computerized Learning Game that Teaches Critical Thinking and Scientific Reasoning." Thinking Skills and Creativity 7 (2): 93-100. http://doi.org/10.1016/j.tsc.2012.03.006.

Kirschner, Paul A. 2002. "Cognitive Load Theory: Implications of Cognitive Load Theory on the Design of Learning." Learning and Instruction 12 (1): 1-10.

Kirschner, Paul A., John Sweller, and Reichard E. Clark. 2006. "Why Minimal Guidance during Instruction Does Not Work: An Analysis of the Failure of Constructivist, Discovery, Problem-Based, Experiential, and Inquiry-Based Teaching." Educational Psychologist 41 (2): 75-86.

Klahr, David, and Kevin Dunbar. 1988. "Dual Space Search during Scientific Reasoning.” Cognitive Science 12: 1-48. http://csjarchive.cogsci.rpi.edu/1988v12/i01/p0001p0048/ MAIN.PDF.

Klahr, David, Corinne Zimmerman, and Jamie Jirout. 2011. "Educational Interventions to Advance Children's Scientific Thinking." Science 333 (6045): 971-75.

Lazonder, Adrianus W., and Angelique Egbrink. 2014. "Children's Acquisition and Use of the Control-of-Variables Strategy: Effects of Explicit and Implicit Instructional Guidance.” Instructional Science 42 (2): 291-304. http://doi.org/10.1007/s11251-013-9284-3.

Lazonder, Adrianus W., and Ruth Harmsen. 2016. "Meta-Analysis of Inquiry-Based Learning: Effects of Guidance." Review of Educational Research 86 (3): 681-718. http://doi.org/10.3102/0034654315627366.

Lim, Jung, Robert A. Reiser, and Zane Olina. 2009. "The Effects of Part-Task and Whole-Task Instructional Approaches on Acquisition and Transfer of a Complex Cognitive Skill.” Educational Technology Research and Development 57 (1): 61-77.

Lorch, Robert F. Jr., Elizabeth P. Lorch, Benjamin Dunham Freer, Emily E. Dunlap, Emily C. Hodell, and William J. Calderhead. 2014. "Using Valid and Invalid Experimental 
Designs to Teach the Control of Variables Strategy in Higher and Lower Achieving Classrooms." Journal of Educational Psychology 106 (1): 18-35.

Mayer, Richard. E. 2005. "Principles for Managing Essential Processing in Multimedia Learning: Segmenting, Pretraining, and Modality Principles." In The Cambridge Handbook of Multimedia Learning, edited by Richard Mayer, 169-82. New York: Cambridge University Press.

Merrill, David M. 2007. “A Task-Centered Instructional Strategy.” Journal of Research on Technology in Education 40 (1): 5-22. http://doi.org/10.1080/15391523.2007.10782493.

Morris, Bradley J., Steve Croker, Amy M. Masnick, and Corinne Zimmerman. 2012. "The Emergence of Scientific Reasoning." In Current Topics in Children's Learning and Cognition, edited by Heidi Kloos, Bradley J. Morris, and Joseph L. Amaral, 61-82. Rijeka, Croatia: InTech.

Murtonen, Mari, and Erno Lehtinen. 2005. "Conceptions of Research and Methodology Learning." Scandinavian Journal of Educational Research 49 (3): 217-24.

Organization for Economic Co-Operation and Development (OECD). 2006. Assessing Scientific, Reading and Mathematical Literacy: A Framework for PISA 2006. OECD. Paris: OECD.

Opitz, Ansgar, Moritz Heene, and Frank Fisher. 2017. "Measuring Scientific Reasoning-A Review of Test Instruments." Educational Research and Evaluation 23 (3-4): 78-101. http://doi.org/10.1080/13803611.2017.1338586.

Osborne, Jonathan, and Justin Dillon. 2008. Science Education in Europe: Critical Reflections. Accessed August 25, 2017. http://efepereth.wdfiles.com/local--files/scienceeducation/Sci_Ed_in_Europe_Report_Final.pdf.

Osborne, Jonathan. 2010. "Arguing to Learn in Science: The Role of Collaborative, Critical Discourse." Science 328 (5977): 463-66.

Rijborz, Daphne. 2003. "Leren Onderzoeken: Leerlijnen bij Praktische Opdrachten in de Tweede Fase in het Profiel Economie \& Maatschappij” [Learning How to Perform Research]. $\mathrm{PhD}$ diss, University of Amsterdam.

Sermeus, Jan, Eli Janssen, Ellen Claes, Fiend Depaepe, and Jan Elen. 2017. "Onderzoekscompetenties: Een Taaie Brok voor Leerlingen in het Secundair Onderwijs" [Research Competences: Difficult for Students in Secondary Education]. Impuls $=>$ (in italics), 48 (1): 13-20.

Stark, Robin, Thomas Puhl, and Ulrieke-Marie Krause. 2009. "Improving Scientific Argumentation Skills by a Problem-Based Learning Environment: Effects of an Elaboration Tool and Relevance of Student Characteristics." Evaluation \& Research in Education 22 (1): 51-68. http://doi.org/10.1080/09500790903082362.

Stern, Leonard D. 2011. "Chapter 14: One-Way Analysis of Variance.” In A Visual Approach to SPSS for Windows: A Guide to SPSS 17.0 (Second Edition), edited by Leonard D. Stern, 269-87. Boston: Allyn \& Bacon.

Stokking, Karel, Marieke van der Schaaf, Jos Jaspers, and Gijsbert Erkens. 2004. "Teachers' Assessment of Students' Research Skills.” British Educational Research Journal 30 (1): 93-116. http://doi.org/10.1080/01411920310001629983.

The Royal Society. 2014. Vision for Science and Mathematics Education. London: The Royal Society.

Van de Koot-Dees, Danielle, Rosa Rodrigues, and Jan Terwel. 2011. "Ik Dacht Ik Ga Gewoon Naar de Middelbare School. Over de Betekenis van Hulpbronnen in de Schoolloopbaan van Leerlingen" [I Thought I Was Just Going to Secondary School. Discussing the Meaning of Resources in Students School Career]. Pedagogiek [Pedagogy] 31 (1): 13554. 
Van Merriënboer, Jeroen J.G. 1997. Training Complex Cognitive Skills: A Four-Component Instructional Design Model for Technical Training. Englewood Cliffs, NJ: Educational Technology Publications.

Van Merriënboer, Jeroen J.G., and Paul A. Kirschner. 2007. Ten Steps to Complex Learning. Hilsdale, NJ: Lawrence Erlbaum Associates.

Van Tilburg, Peter A., and Nico Verloop. 2000. "Kennis van en Opvattingen over het Onderwijzen van Onderzoeksvaardigheden" [Knowledge of and Opinions on the Teaching of Research Skills]. Tijdschrift voor Didactiek der Beta-wetenschappen 17 (1): $60-75$.

Wagner, Claire, Mark Garner, and Barbara Kawulich. 2011. "The State of the Art of Teaching Research Methods in Social Science: Towards a Pedagogical Culture.” Studies in Higher Education 36 (1): 75-88. http://doi.org/10.1080/03075070903452594.

Zimmerman, Corinne. 2000. "The Development of Scientific Reasoning Skills.” Developmental Review 20 (1): 99-49. http://doi.org/10.1006/drev.1999.0497. 2005. "The Development of Scientific Reasoning Skills: What Psychologists Contribute to an Understanding of Elementary Science Learning." Accessed June 23, 2017. https://www.researchgate.net/publication/253485694_The_Development_of_Scientific Reasoning_Skills_What_Psychologists_Contribute_to_an_Understanding_of_Elementa ry_Science_Learning.

2007. "The Development of Scientific Thinking Skills in Elementary and Middle

School.” Developmental Review 27 (2): 172-223.

http://doi.org/10.1016/j.dr.2006.12.001.

\section{ABOUT THE AUTHORS}

Eli Janssen: PhD Candidate, Faculty of Social Sciences, Centre for Political Research, KU Leuven, Leuven, Belgium

Fien Depaepe: Assistant Professor, Faculty of Psychology and Educational Sciences, Centre for Instructional Psychology and Technology KU Leuven, Leuven, Belgium

Ellen Claes: Assistant Professor, Faculty of Social Sciences, Centre for Political Research, KU Leuven, Leuven, Belgium

Jan Elen: Full Professor, Faculty of Psychology and Educational Sciences, Centre for Instructional Psychology and Technology, KU Leuven, Leuven, Belgium 